\title{
Preparation of students and residents of human medicine in the first four months of the Covid-19 pandemic. Implications for a second wave.
}

Benny Wohlfarth ( $\sim$ benny.wohlfarth@insel.ch )

Inselspital, Bern University Hospital https://orcid.org/0000-0002-4857-2636

Beat Gloor

Inselspital, Bern University Hospital

Wolf Hautz

Inselspital, Bern University Hospital

\section{Systematic Review}

Keywords: covid-19, pandemic, medical education, deployment, redeployment, professional identity formation, students, trainees, residents

Posted Date: November 11th, 2020

DOl: https://doi.org/10.21203/rs.3.rs-105577/v1

License: (c) (1) This work is licensed under a Creative Commons Attribution 4.0 International License. Read Full License 
Title: $\quad$ Preparation of students and residents of human medicine in the first four months of the Covid-19 pandemic. Implications for a second wave.

Name: $\quad$ Dr. Benny Wohlfarth

Work address: Department of Visceral Surgery and Medicine, Inselspital, Bern University Hospital, University of Bern, Freiburgstrasse 18, 3010 Bern, Switzerland

Contact: $\quad$ benny.wohlfarth@insel.ch

Name: $\quad$ Prof. Dr. Beat Gloor

Work address: Department of Visceral Surgery and Medicine, Inselspital, Bern University Hospital, University of Bern, Freiburgstrasse 18, 3010 Bern, Switzerland

Contact: $\quad$ beat.gloor@insel.ch

Name: $\quad$ Prof. Dr. Wolf Hautz

Work address: $\quad$ Department of Emergency Medicine, Inselspital, Bern University Hospital, University of Bern, Freiburgstrasse 18, 3010 Bern, Switzerland

Contact: $\quad$ wolf.hautz@insel.ch 


\section{Abstract}

Introduction: In the Covid-19 pandemic, medical students and residents find themselves in a healthcare environment with measures and policies changing by the hour. Reports regarding those in training were scarce and scattered in the early pandemic, what made an overarching insight a challenge. This review compiles and analyzes the literature addressing the preparation of students and residents in the first four months of the Covid19 pandemic to find gaps and implications for the current pandemic as well as for future scenarios.

Methods: We performed a systematic literature search and content analysis (CA) for articles available in English language that focus on the preparation of students and residents in human medicine within the first four months of the Covid-19 pandemic.

Results: We retrieved 82 articles from a wide range of journals, professional backgrounds and countries. CA identified five recurring subgroup topics of «faculty preparation», «uncertainty and mental health», "clinical knowledge», "rights and obligations» and "(self-) support and supply». Within these subgroups the main concerns of «(re)deployment», «interruption of training and career», "safety issues», «transmission of disease», and «restricted social interaction» were identified as potential stressors that hold a risk for fatigue, loss of morale and burnout.

Discussion: Students and residents are willing and able to participate, when provided with appropriate deployment, thorough supervision, Personal Protective Equipment (PPE) and valid knowledge. Faculties and policymakers should be in close contact with the youngest in training to value their concerns and intrinsic creativity on the scenario. The use of new technology for interaction and knowledge provision, interviews for voluntary deployment and the provision of mental health support seem appropriate measures to support students and residents under the current pandemic.

Conclusion: Our review holds thorough implications for faculties and policymakers. Not only for surge capacity, but also for the safety and the professional identity formation of those in training, it is crucial to understand their needs and concerns. Leaders should strive for a close communication with students and residents, value their intrinsic creativeness and constantly evaluate on their needs regarding knowledge aspects, safety measures, legal concerns and well-being for the construction of nation-wide homogenous policies. 


\section{Introduction}

The corona virus disease 2019 (Covid-19) due to Severe Acute Respiratory Syndrome Corona Virus 2 (SARS-CoV-2) evolved into an infectious disease of pandemic proportion [1]. Medical students and residents around the globe find themselves in a healthcare environment with measures and policies changing by the hour.

Reports regarding the preparation of those in training were scarce and scattered in the beginning, what made overarching insights a challenge.

While there is an abundance of information for those in training from bygone epidemic and pandemic scenarios [2, 3], these were nowhere near the same historical momentousness we are facing right now.

The last pandemic of similar proportions, the Spanish flu [4], occurred around the end of the life of William Osler. Modern medical education was still in its infancy and the setting, compared to today's globalized life and available technology, differed significantly, holding only sparse implications for today's scenario.

This review compiles and analyzes the literature that addresses the preparation of students and residents in the first four months of the Covid-19 pandemic to find gaps and implications for a pandemic that might go on for years [ $\underline{5}$ ] as well as for future scenarios.

\section{Methods}

We retrieved articles in English language focusing on the challenges in preparation of students and residents in human medicine within the first four months of the pandemic. With Wuhan Health Authorities initially reporting on December 312019 [6], we set the timeframe for the literature search from January 12020 accordingly. The main search was performed via PubMed, resulting in 1108 articles. After exclusion of inappropriate articles, we ended up with 162 student- and resident-related articles. We then excluded 80 more articles, solely focusing on the adaptation of curricula (e.g. moving classes online [7]), resulting in a final pool of 82 articles. [s. Figure 1]. 


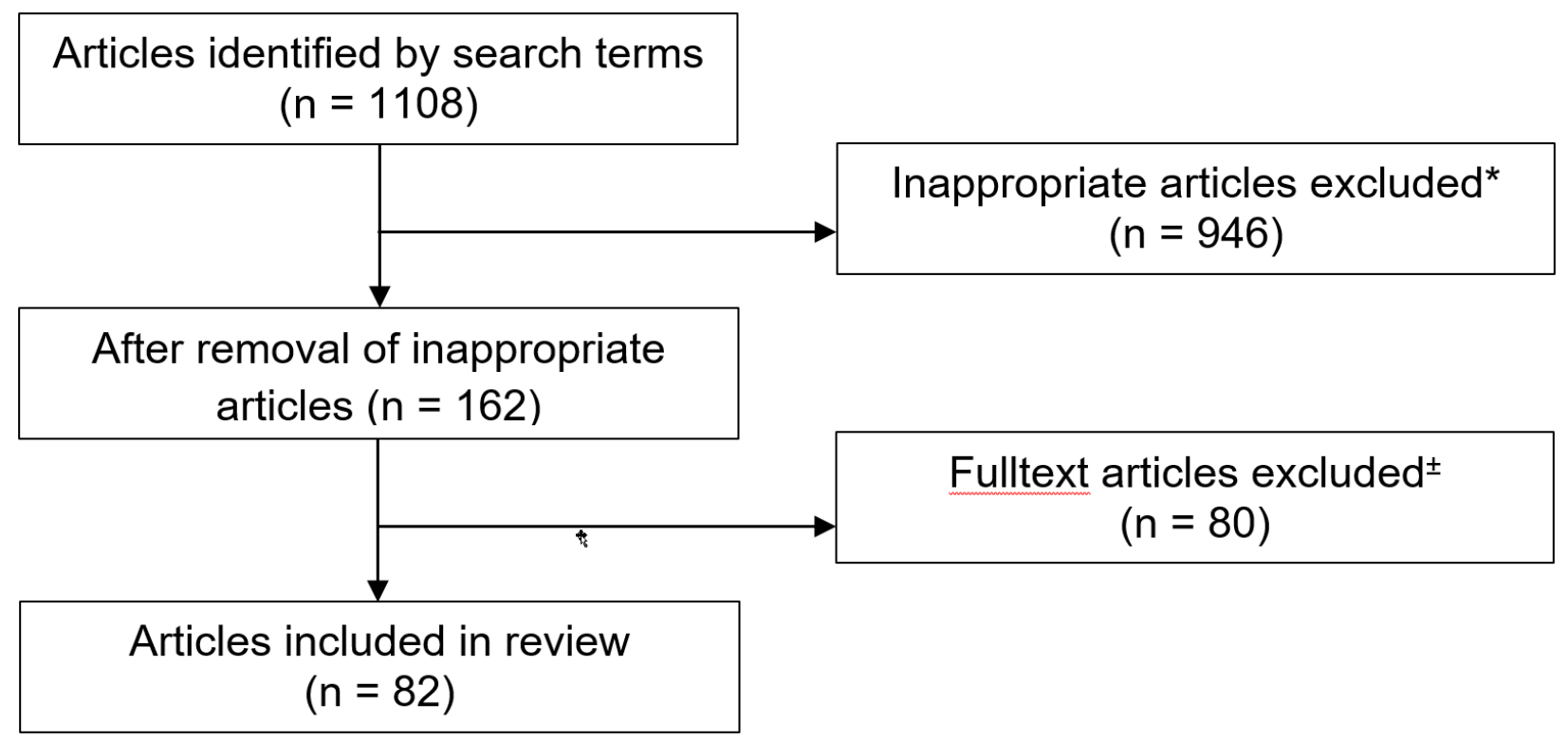

[Figure 1: process flowchart of article selection] "inappropriate articles primarily resulted from articles in the pandemic that refer to 1. Residents and residency in terms of inhabitants or 2. Students, not in the sense of medical students or 3. Education, not in the sense of medical education. ${ }^{ \pm}$exclusion of articles solely dealing with adaptation of curricula.

BW reviewed titles, abstracts, and full text of the final articles and performed a content analysis (CA) using the Gemba-Kaizen Framework.

Originally, Gemba-Kaizen is a concept from lean management [8]. The word Gemba translates to "actual place" describing the site where value-creating work takes places effectively (e.g. production halls). Gemba mediates that real life observations of frontline processes are necessary to understand and improve workplace situations.

Owing to the fact, that the current pandemic is unprecedented, the Gemba-Kaizen represents a highly appropriate framework for the current scenario where frontline reports are often the only source available. Therefore, we performed a virtual Gemba-Walk through the retrieved literature, considering the five rules of Gemba [9] for our CA:

- Looking up the scenario

- Assessment of problems

- Find initial countermeasures

- What is the root cause/gap?

- Find implications for transferable solutions

Furthermore, we extracted metadata accompanying the articles to understand the overall perception and background of the topic, including publication rate, types of articles, professional background and country of residency of the first author. 


\section{Results}

General results and publication rate over time

Overall, 82 articles covered our topic. Within this group $70.7 \%(n=58)$ articles solely and $29.3 \%(n=24)$ so called hybrid articles, partly dealt with the preparation of students and residents in the first four months of the Covid-19 pandemic.

Before March 11 2020, we only identified one appropriate article. From March 132020 onwards, publication rate increased significantly, up to 82 articles on 30 April 2020 [s. Figure 2].

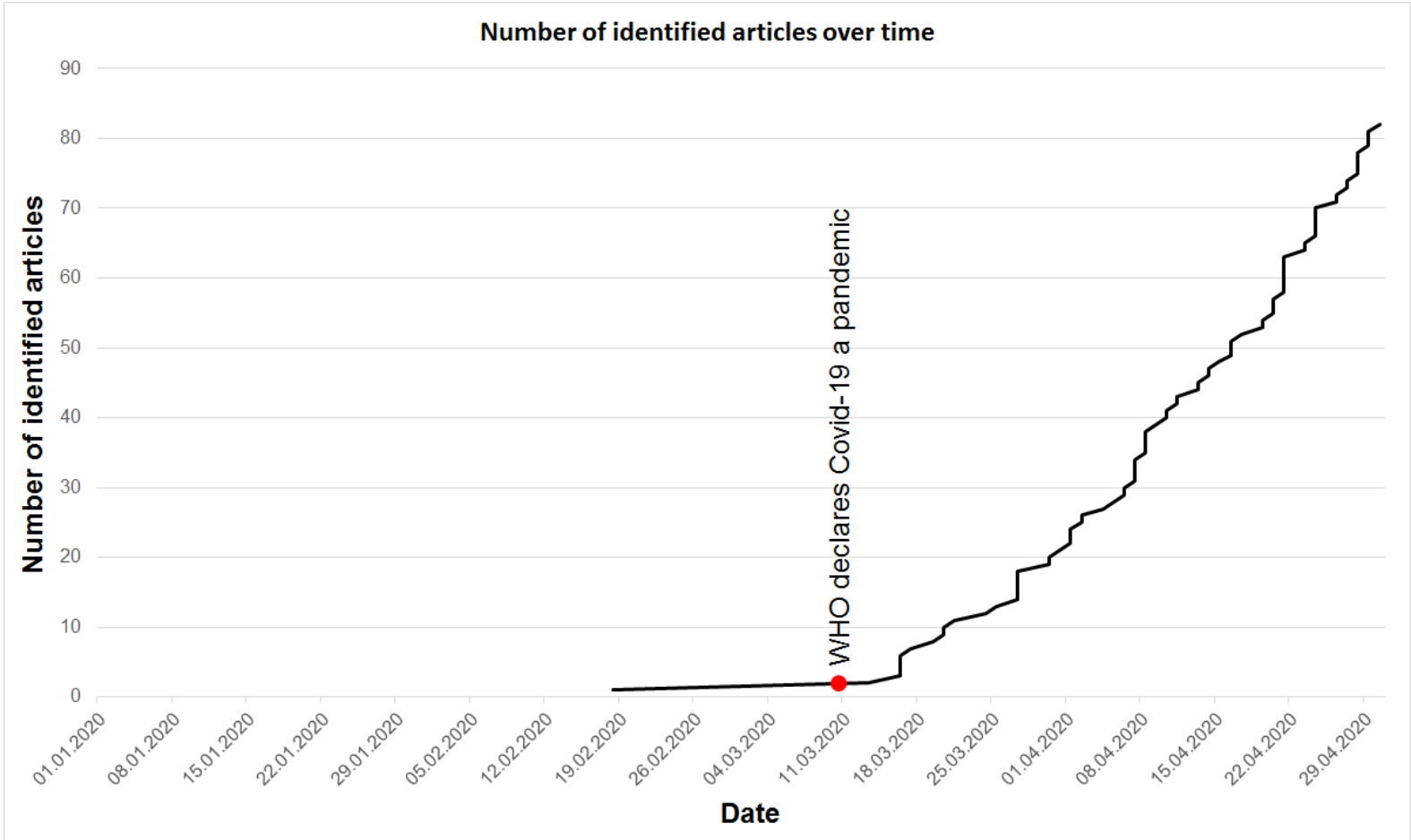

[Figure 2: Number of identified articles over time]

\section{Metadata analyzation of retrieved articles}

We ranked the results from metadata analyzation according to professional background of the first author, country of residency of the first author and types of articles [s. Table 1]. 


\begin{tabular}{|c|c|c|c|c|c|}
\hline $\begin{array}{l}\text { Professional } \\
\text { background of } \\
\text { first author }\end{array}$ & $\begin{array}{l}\text { No. of } \\
\text { articles }\end{array}$ & $\begin{array}{l}\text { Country of } \\
\text { residence of } \\
\text { the first author }\end{array}$ & $\begin{array}{l}\text { No. of } \\
\text { articles }\end{array}$ & Type of article & $\begin{array}{l}\text { No. of } \\
\text { articles }\end{array}$ \\
\hline Medical Student & $(n=10)$ & USA & $(n=43)$ & Letter & $(n=15)$ \\
\hline Internal Medicine & $(n=8)$ & UK & $(n=14)$ & Commentary & $(n=14)$ \\
\hline Medical Journalist & $(n=8)$ & Australia & $(n=2)$ & Study & $(n=12)$ \\
\hline Orthopedic Surgery & $(n=7)$ & Canada & $(n=2)$ & News & $(n=7)$ \\
\hline Neurosurgery & $(n=5)$ & Denmark & $(n=2)$ & Editorial & $(n=5)$ \\
\hline Radiology & $(n=5)$ & Iran & $(n=2)$ & Perspectives & $(n=5)$ \\
\hline Dermatology & $(\mathrm{n}=4)$ & Singapore & $(n=2)$ & Correspondence & $(n=4)$ \\
\hline Emergency & $(n=3)$ & South Korea & $(n=2)$ & Opinion & $(n=4)$ \\
\hline Infectious Diseases & $(n=3)$ & UAE & $(n=2)$ & Career & $(n=3)$ \\
\hline Head and Neck & $(n=3)$ & Others & $(n=11)$ & Innovation & $(n=2)$ \\
\hline Surgery & $(n=3)$ & Total & $(n=82)$ & Medical Education & $(n=2)$ \\
\hline Anesthesiology & $(n=2)$ & & & Special Article & $(n=2)$ \\
\hline Cardiology & $(n=2)$ & & & Others & $(n=7)$ \\
\hline Psychiatry & $(n=2)$ & & & Total & $(n=82)$ \\
\hline Psychology & $(n=2)$ & & & & \\
\hline Others & $(n=15)$ & & & & \\
\hline Total & $(n=82)$ & & & & \\
\hline
\end{tabular}

[Table 1: Results of metadata analyzation]

\section{Coding results}

Looking up the scenario

Within the retrieved articles, we identified five subgroup topics in our CA [s. Table 2].

\begin{tabular}{|l|l|}
\hline Coded subgroup & $\begin{array}{l}\text { No. of } \\
\text { articles }\end{array}$ \\
\hline Faculty preparation & $(\mathrm{n}=34)$ \\
\hline Uncertainty and mental & $(\mathrm{n}=24)$ \\
\hline Clinical knowledge & $(\mathrm{n}=10)$ \\
\hline Rights and obligations & $(\mathrm{n}=9)$ \\
\hline (Self-)support and supply & $(\mathrm{n}=5)$ \\
\hline Total & $\mathbf{8 2}$ \\
\hline
\end{tabular}

[Table 2: Coded subgroups]

\section{Coded subgroups}

\section{Assessment of problems and initial countermeasures}

\section{Faculty preparation}

With $41.5 \%(n=34)$ of articles, Faculty preparation was the most prominent subgroup topic. Initial countermeasures ranged from single actions to complete workplace solutions [1019]. Several departments, including their residents, started working in waves of alternating teams to avoid a complete breakdown in case of an outbreak amongst employees. While some were doing hospital service, others continued working from home, helping and advising on inpatients remotely or doing telemedicine appointments on outpatients [15]. 
To address the problem of surge capacity, students were suggested to be deployed to information lines, epidemiological information services, childcare for frontline workers, volunteers in laboratory work, screening clinics, contact tracing or even in the clinical setting. Here, discussions ranged from care of non-infected patients and low-acuity Covid19 scenarios to introduction in ventilator therapy or nursing assistance [13, 20-26]. For clinical deployment, final year students were given early registration, temporary license or allowed to work as physician assistants in several countries [13, 23, 25, 27-31].

Yet, the clinical deployment of students has been seen ambivalent. Some echoing safety concerns [32] while others consider clinically deployed students as a major help for frontline workers to focus on the fight of the pandemic and therefore ensuring surge capacity [33]. Additionally, some educators see a critical chance for the Professional Identity Formation (PIF) of students in the pandemic including altruism, service in times of crisis and solidarity with their profession [34, 35].

Residents from non-frontline specialties, were often given the option to work, train or research from home or to apply on a voluntary basis for redeployment [29, 36]. In analogy to the students scenario, preexisting concerns that residents are often less likely to receive a standard training for potential mass casualties, compared to nurses and attendings, have been brought up again [37-39].

Furthermore, initial countermeasures included first guidelines for residency programs [40] and adapted article series from medical education journals [41].

\section{Uncertainties and mental health}

Uncertainties and mental health represent the second most covered topic $(29.2 \%(n=24))$. In an early study, looking at the impact of Covid-19 on students, $24.9 \%$ showed raised levels of anxiety. Namely, the related stressors were of economic nature, affection of daily life and academic delays [42]. Though this study was criticized for non-consideration of confounding factors [43], it is undeniable that Covid-19 related measures have an impact on mental health. Social distancing and isolation are important stressors that are perceived as having a negative impact [44]. The disruption of training programs, reduced practical workload in a residents specialty, slowdown of research careers and redeployment are further stressors that may bring burnout, fatigue and loss of morale [4547]. Residents also were concerned that the pandemic would adversely affect their completion of training and nearly half the respondents had an anxious feeling about their training future [48]. Also, more than half of the residents that were deployed in a workplace beyond their usual scope of work showed high levels of stress, and anxiety was reported frequently $[1 \underline{3}, \underline{18}, \underline{48}]$.

Additionally, due to the potential risk of being vectors, residents worry about a possible disease transmission to their families and patients [13, 44, 49-56]. The fear of being vectors becomes more understandable, considering the other main concerns of residents, namely PPE shortage, vague instructions, limited testing capacities, frequently changing policies and the danger of mental exhaustion $[\underline{54}, \underline{56}]$. In accordance to inexperience and insecurities, the critical questions about the acceptable level of risk and who determines this level arised [56]. This question seems crucial especially as junior are having a potentially higher risk to be redeployed compared to seniors [57].

Students are also at potential risk to become vectors $[22,58]$ and they are aware of that [23]. By analogy to residents' concerns, PPE shortage was also a main concern for students [묘. 
Social support seems to reduce levels of anxiety [42] and staying connected in times of social distancing deems important [44]. Furthermore, the social aspect of discussion with peers can also reduce anxiety and stress [35]. Here, early countermeasures included residents having a daily informal video conference to have a social connection to peers while practicing social distancing [16].

\section{Clinical knowledge}

General medical knowledge, about the disease, and the virus itself were covered in $12.2 \%$ $(n=10)$ of articles. Healthcare workers, including residents and students, revealed an inhomogeneous knowledge about the pandemic, with most in the need of improvement [59-62] and a few in good preparation [63, 64].

Questions for every clinical aspect in the context of Covid-19, reaching from basic uncertainties to cardiopulmonary resuscitation (CPR) [56, 65] and even autopsy [66], were raised. Initial countermeasures, like senior residents establishing 'Quick sheets' about Covid-19 to keep their peers up to date, were established [67]. Radiologists where the first to explicitly foster the education about image findings towards their trainees in publications [68]. Likewise, anesthesiologists published early on practical knowledge about the disease, also addressing their trainees [69]. Nevertheless, a major challenge in retrieving valid knowledge lied in the fact, that students and residents make use of social media as a source of information frequently [59], which holds a potential risk of misinformation.

\section{Rights and obligations}

We found $11 \%(n=9)$ of articles dealing with legal orientation. Amongst the main concerns were the legal handling of training interruption, redeployment, cancellation of exams and subsequently deriving consequences $[\underline{22}, \underline{30}, \underline{53}, \underline{58}, \underline{70}]$. Some countries temporarily put postgraduate rotation on hold and residents stayed in their current workplace with the potential exception of redeployment to areas of need [71]. For students, various organizations released statements to stop contact with patients to avoid unnecessary risks of infection. Correspondingly, students were excluded from clinical training in several countries, yet clinical deployment against Covid-19 was taken into account [30, $\underline{58}, \underline{72}]$, what caused irritation and raised demands for congruent guidance. A complicating factor was the usage of social media, frequently exposing students and residents to misinformation about rights and obligations, worsening insecurities [22].

\section{(Self-)support and supply}

Many articles reflected the willingness from students and residents to help [23, $\underline{30}, \underline{35}, \underline{43}$, $\underline{52}, 73]$. In terms of tangible actions supporting their peers, $6.1 \%(n=5)$ of articles solely, and four articles partly, covered this topic.

Next to measures aiming at clinical knowledge [67], one major topic was the deployment to appropriate tasks. Therefore, junior doctors began compiling support lists, with tasks that could be done from home and a university's medical society created a group to direct students willing to volunteer [30]. Students formed response teams to mobilize and deploy peers for voluntary work in adequate positions. This was done in close contact with administrations and faculties to recognize evolving needs and engage appropriately [74]. Furthermore, students formed various groups on social media to brainstorm ideas [23]. 
Practical examples here ranged from childcare to meal preparation inter alia for frontlineworkers [22].

Long working hours hindered several students and residents to gather daily needed supplies. Therefore, residents began to set up supply boxes correspondingly [75].

Chief residents came up with a 5 question compilation to adapt preparation programs for new residents accordingly [76] and some students were also amongst a group of volunteers constructing plastic face shields for frontline clinicians [77].

\section{Discussion}

\section{General results and publication rate over time}

Publications were scarce until early March 2020. After the WHO declaration on March 11 2020 [1] we saw a profound increase in publications. We assume that the WHO declaration marked an important step for awareness and acted as an initiation for publication on the topic. Not surprisingly, only $14.6 \%(n=12)$ of articles were studies while the majority were short forms of communication. Laudably, most publications were freely available. We consider this a highly regarded proceeding valuing the importance of the young workforce.

\section{Most prolific background}

Students are highly prolific in sharing their thoughts and experience on the topic and their input holds invaluable information for faculties and policymakers.

The participation from the backgrounds of internal medicine, emergency medicine and anesthesiology with their frontline involvement also holds invaluable implications for improvement. Interestingly enough, specialties remote to the aforementioned core competencies to fight Covid-19 have also been very active. We do not only see this in the light of concernedness for redeployment but also as an intrinsic motivation to help when it comes to medical crisis.

\section{Most prolific country}

Publications were strongly dominated by Anglo-Saxon countries. To broaden the insight, a deeper involvement of other countries would have been desirable. Especially countries like China, Italy and Iran could supply invaluable information. Yet, we understand that priorities and resources were focused on frontline activities over the first four months.

\section{Most frequent article types}

Here, short communication forms clearly outrun complex studies and reviews. Due to the unprecedented situation, initial sharing of information was preferably done via quick communication forms like letters and commentaries, showing the eagerness for a rich discussion. Moreover, though the first few studies were mostly survey-based, they must not be underestimated, delivering the first forms of evidence, especially on the mindset and perception of the pandemic from students and residents.

\section{Coded subgroups}

$\underline{\text { Root causes, gaps and implications for transferable solutions }}$

\section{Faculty preparation}


Owing to the large amount of articles in this subgroup, it is safe to say that faculties recognized the vast importance of the topic.

With an initial root cause to ensure surge capacity, a major challenge lies within the appropriate and timely preparation of students and residents, while considering their concerns. These involved the conscientious provision of PPE, adequate knowledge provision and an attentive deployment outside of their clinical competencies [77].

Students should not be put in situations exceeding their competencies, have adequate access to PPE and should be deployed on a voluntary basis [30, 32, $\underline{78}$. First year residents, in deployment or new roles within their clinic, need to be supervised accordingly $[16, \underline{27}]$.

Being possible vectors, residents on duty should have the chance to reduce physical movement. One transferable approach reported was to batch emergency department (ED) consultations from specialties if possible and strictly limit the number of residents visiting Covid-19 positive patients during ward rounds [16].

Proper preparation should involve new technology. Simulation, due to its potential of lowering cognitive load, might be of help for redeployment of residents to the frontline [79], telemedicine can be used to combine patient care with education of residents and students [80].

For an appropriate deployment of students, interviews may represent an adequate tool to identify volunteers with the right intentions [34] and skills [30]. Within these interviews, aptitudes and motivation can also be recognized and give applicants the chance to fill in meaningful roles.

The possibilities are manifold and the input from students and residents hold invaluable information for faculties and policymakers. In regards to this, regular online meetings between students, residents and program directors have been a solution to sense the impact of change or redeployment and help to decide on necessary actions $[14, \underline{29}, \underline{81}$.

A thorough preparation on mass casualties should be equally provided for students and residents as it has been for nurses and attendings [37-39]. Also, to avoid shortage of staff, an upcoming possible lack of foreign exchange residents due to travel restrictions also needs to be addressed [82].

Students and residents are willing to participate yet faculties and policymakers have to recognize their concerns as well as their ideas. Thorough safety measures and supervision are mandatory for a successful deployment of students and residents. With the warranty of such measures, the current pandemic holds an invaluable chance for a successful (re)deployment and an important contribution for the Professional Identity Formation of the youngest in training.

\section{Uncertainties and mental health}

Several stress- and anxiety-related studies on Covid-19 came up with a profound negative impact on students and residents that needs to be addressed conscientiously for optimal preparedness and resilience $[42, \underline{73}]$.

One major uncertainty is redeployment. While half of deployed residents felt well equipped in one survey [48], and redeployment can also be perceived as an opportunity of personal growth and introspection [51], there is still room for improvement. A major factor on how redeployment is received may lie in the form of selection. Reports indicate that voluntarily deployed residents feel well-protected and trained [83]. This is of great interest as raised stress levels in presumably non-voluntary redeployment and training hold a risk for 
burnout, that needs to be watched and addressed [48]. For an optimal allocation, confidential interviews could assess on issues that may have a negative impact on the resident or their family (e.g. immunosuppression). Deployment should consider such information accordingly [46]. Additionally, a sufficient Covid-19 testing capacity for staff, PPE and feasible shift schedules are seen as viable to reduce exposure and prevent burnout [50].

One study showed that social support was negatively correlated with levels of anxiety in students [42]. Others underlined the importance and positive impact of good teamwork [83] and the benefits of online-meetings to stay connected and relieve stress [29]. The general possibility to consult mental health support provided by the institution seems sensible [16] and psychiatrist should be aware of concerns and thoughts from frontline workers [44]. A physical way to relieve stress was the adaptation of a former fitness program, changed into a home exercise routine where results were shared via an online group [14]. Furthermore, FAQs provided by journals represented another form of support in redeployment [84].

Most of the aforementioned concerns also apply for students. Additionally, competency based medical education could help to prepare students for healthcare crisis like the current pandemic [49].

Leaders should stay in close contact with students and residents to supply information and emotional support [53]. Next to a transparent communication, safety measures, teamwork culture, mental health support and a solid infrastructure for communication technology to secure remote social interaction seem viable actions to diminish uncertainties, relieve stress and make the young workforce more effective in unprecedented times.

\section{Clinical knowledge}

The knowledge about SARS-CoV-2 and Covid-19 is steadily evolving. To keep students and residents up to date, it is necessary to provide valid knowledge via channels they commonly use. With the vast majority of them being digital natives, most get their knowledge via online platforms and social media [59]. In addition to that, it was shown that focused training courses (held offline before, and online after lockdown) could significantly enhance the knowledge about Covid-19 [85] and that there was no difference in quality between instructor-led and video lesson based instruction on PPE [86]. Local solutions like the 1-sided 'Quick sheet' amongst residents was soon be adopted by the whole department [67] and may also be a valuable transferable solution to other departments. Faculties, educators and journals should foster the spread of valid clinical knowledge on social media and other digital solutions (e.g. online courses, chats and video conferences) as a mainstay for knowledge transfer. Fast realization and relative inexpensiveness make such outlets even more attractive.

\section{Rights and obligations}

Students and residents need clear information on rights and obligations. The root cause veining insecurity in the pandemics' beginning were its dynamic and concomitant disorientation, worsened due to unconfirmed news, primarily spread via social media. Official organs should use their assertiveness and presence as valid resource centers. We found various transferable solutions in actions, like UK training bodies providing guidance principles for all trainees on redeployment, training disruption and its 
consequences with a useful link collection [70] and journals compiling 'frequently asked questions' (FAQ) [45, 87]. Yet, for a better dissemination and to counteract rumors, such articles should be prominently placed on social media [59].

For a possible deployment to the frontline, the British Medical Association (BMA)

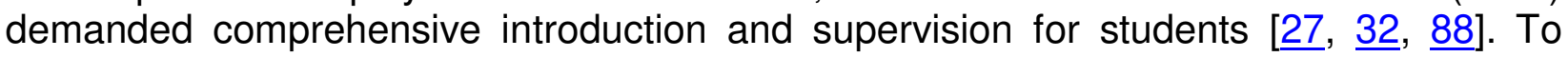
minimize career disadvantages for the redeployed, several ideas, like a governmentprovided loan repayment or discounting of final-year tuitions, were suggested [89, 90].

In Canada, though final exams were postponed, the Royal College of Physicians and Surgeons affirmed that students graduating this year will still be able to enter residency and to obtain a license [31].

Policymakers should strive for nation-wide homogenous approaches to ensure equal opportunities and avoid disadvantages in education and career for the redeployed [91]. Finally, it should not be forgotten that, despite the undisputed importance of legal aspects, there is also an ethical and moral bound to help [92].

\section{(Self-)support and supply}

The root for the extensiveness of self-supportive measures partly lies within the dynamic and unprecedentedness where many problems were just realized underway by those concerned. Initiatives, like supply-boxes are not only directly helpful, but also strengthen the sense of community. Understandably, it found an overwhelming positive response [75] and represents an easily transferable solution. The reported student response team to optimize the mobilization of peers was also a huge success and shared to several medical schools [74].

The general supportiveness of students and residents were known long before Covid-19. Yet, current situation rekindled the discussion if we may need a longitudinal social justice and advocacy framework in medical school for an even better preparation [93]. Furthermore, a nationwide coordination has been suggested for a homogenous form of practical help [23].

The retrieved articles clearly show that students and residents have an intrinsic ability to adapt creatively to unprecedented scenarios. The implementations of self-supporting measures strengthen the feeling of community within their peer group and hold invaluable information for faculties and policymakers.

\section{Limitations}

This review has several limitations. As the Covid-19 pandemic is a current scenario, longterm insights and evidence, especially on complex educational aspects, considering interdependencies, teamwork and competency are non-existent. Therefore, our review is mostly build on frontline experience and is in no way exhaustive. Several articles in this review may hold a bias of subjectivity and overrepresented unilateral views. Publication was strongly dominated by Anglo-Saxon countries, holding a possible bias or nontransferable implications for other countries. Especially the input on rights and obligations - mainly from the United Kingdom - may not apply to foreign legislations. Nevertheless, we believe that echoing all available, yet restricted or unilateral information richens the discussion and broadens the insight on a topic of global concern.

\section{Conclusion}


The Covid-19 pandemic is not only a challenge but also a chance to change the situation for students and residents for the better. Never has it been easier to raise awareness for their concerns. Never have the barriers been lower to implement new policies and technology that can help to improve the transition of the young workforce into the field of medicine in times of crisis.

Our review of the literature hold thorough implications for faculties and policymakers. Not only for surge capacity to fight the pandemic, but also for the safety and the professional identity formation of students and residents, it is crucial to understand their needs and concerns. Leaders should strive for a close communication with students and residents, value their intrinsic creativeness on support and constantly evaluate on their needs in regards to knowledge aspects, safety measures, legal concerns and well-being. 


\section{References}

1. WHO Director-General's opening remarks at the media briefing on COVID-19 - 11 March 2020 [https://www.who.int/dg/speeches/detail/who-director-general-sopening-remarks-at-the-media-briefing-on-covid-19---11-march-2020]

2. Chen PT, Huang YC, Cheng HW, Wang CC, Chan CY, Chan KH, Kuo CD: New simulation-based airway management training program for junior physicians: Advanced Airway Life Support. Medical teacher 2009, 31(8):e338344.

3. Wong TW, Tam WW: Handwashing practice and the use of personal protective equipment among medical students after the SARS epidemic in Hong Kong. American journal of infection control 2005, 33(10):580-586.

4. Honigsbaum M: Spanish influenza redux: revisiting the mother of all pandemics. Lancet (London, England) 2018, 391(10139):2492-2495.

5. The COVID-19 pandemic could last for 2 years, according to US experts [https://www.weforum.org/agenda/2020/05/coronavirus-pandemic-last-2-years/]

6. Pneumonia of unknown cause - China [https://www. who.int/csr/don/05january-2020-pneumonia-of-unkown-cause-china/en/]

7. Gaber DA, Shehata MH, Amin HAA: Online team-based learning sessions as interactive methodologies during the pandemic. Medical education 2020, $\mathbf{n} / \mathbf{a}(\mathrm{n} / \mathrm{a})$.

8. Ohno T: Toyota Production System: Beyond Large-Scale Production: Productivity Press; 1988.

9. Imai M: Gemba Kaizen. A Commonsense, Low-Cost Approach to Management. In: Das Summa Summarum des Management: Die 25 wichtigsten Werke für Strategie, Führung und Veränderung. edn. Edited by Boersch C, Elschen R. Wiesbaden: Gabler; 2007: 7-15.

10. Alvin MD, George E, Deng F, Warhadpande S, Lee SI: The Impact of COVID-19 on Radiology Trainees. Radiology 2020, 0(0):201222.

11. Ebben S, Hussain RA, Miloro M, Callahan N: The UIC COVID Coverage Protocol: A Technical Note for Pandemic Oral and Maxillofacial Surgery Call Coverage. Journal of oral and maxillofacial surgery : official journal of the American Association of Oral and Maxillofacial Surgeons 2020.

12. Eichberg DG, Shah AH, Luther EM, Menendez I, Jimenez A, Perez-Dickens M, O'Phelan KH, Ivan ME, Komotar RJ, Levi AD: Letter: Academic Neurosurgery Department Response to COVID-19 Pandemic: The University of Miami/Jackson Memorial Hospital Model. Neurosurgery 2020.

13. Armstrong A, Jeevaratnam J, Murphy G, Pasha M, Tough A, Conway-Jones R, Mifsud RW, Tucker S: A plastic surgery service response to COVID-19 in one of the largest teaching hospitals in Europe. Journal of plastic, reconstructive \& aesthetic surgery : JPRAS 2020.

14. Weber AC, Henderson F, Jr, Santos JM, Spiotta AM: Letter: For Whom the Bell Tolls: Overcoming the Challenges of the COVID Pandemic as a Residency Program. Neurosurgery 2020.

15. Bray DP, Stricsek GP, Malcolm J, Gutierrez J, Greven A, Barrow DL, Rodts GE, Gary MF, Refai D: Letter: Maintaining Neurosurgical Resident Education and Safety During the COVID-19 Pandemic. Neurosurgery 2020. 
16. Ammar A, Stock AD, Holland R, Gelfand $Y$, Altschul D: Managing a Specialty Service During the COVID-19 Crisis: Lessons From a New York City Health System. Academic Medicine 2020, Publish Ahead of Print.

17. Park JS, El-Sayed IH, Young VN, Pletcher SD: Development of clinical care guidelines for faculty and residents in the era of COVID-19. Head \& Neck 2020, $\mathbf{n} / \mathbf{a}(\mathrm{n} / \mathrm{a})$.

18. Phillips CD, Shatzkes DR, Moonis G, Hsu KA, Doshi A, Filippi CG: From the Eye of the Storm: Multi-Institutional Practical Perspectives on Neuroradiology from the COVID-19 Outbreak in New York City. American Journal of Neuroradiology 2020.

19. Konda SR, Dankert JF, Merkow D, Lin CC, Kaplan DJ, Haskel JD, Behery O, Crespo A, Ganta A: COVID-19 Response in the Global Epicenter: Converting a New York City Level 1 Orthopedic Trauma Service into a Hybrid Orthopedic and Medicine COVID-19 Management Team. Journal of Orthopaedic Trauma 2020, Publish Ahead of Print.

20. Iserson KV: Augmenting the Disaster Healthcare Workforce. The western journal of emergency medicine 2020, 21(3):490-496.

21. Villela EFdM, de Oliveira FM, Leite ST, Bollela VR: Student engagement in a public health initiative in response to COVID-19. Medical education 2020, $\mathrm{n} / \mathbf{a}(\mathrm{n} / \mathrm{a})$.

22. Anna Harvey: Covid-19-Medical students face disruption and uncertainty [https://blogs.bmj.com/bmj/2020/03/16/anna-harvey-covid-19-medical-studentsface-disruption-and-uncertainty/]

23. Thomson E, Lovegrove S: 'Let us Help'-Why senior medical students are the next step in battling the COVID-19 Pandemic. International Journal of Clinical Practice 2020, n/a(n/a):e13516.

24. Wilson AN, Ravaldi C, Scoullar MJL, Vogel JP, Szabo RA, Fisher JRW, Homer CSE: Caring for the carers: Ensuring the provision of quality maternity care during a global pandemic. Women and birth : journal of the Australian College of Midwives 2020.

25. Rasmussen S, Sperling P, Poulsen MS, Emmersen J, Andersen S: Medical students for health-care staff shortages during the COVID-19 pandemic. Lancet (London, England) 2020, 395(10234):e79-e80.

26. Oxford medical students step-up to support fight against Covid-19 [http://www.ox.ac.uk/news/2020-03-23-oxford-medical-students-step-supportfight-against-covid-19]

27. Harvey A: Covid-19: medical students and FY1 doctors to be given early registration to help combat covid-19. BMJ 2020, 368:m1268.

28. NYU offers early graduation to senior med students in bid to fight coronavirus. [nypost.com/2020/03/24/nyu-offers-early-graduation-to-senior-medstudents-in-bid-to-fight-coronavirus/ ]

29. Schwarzkopf R, Maher NA, Slover JD, Strauss EJ, Bosco JA, Zuckerman JD: The Response of an Orthopedic Department and Specialty Hospital at the Epicenter of a Pandemic: The NYU Langone Health Experience. The Journal of arthroplasty 2020.

30. Mahase E: Covid-19: medical students to be employed by NHS. BMJ 2020, 368:m1156. 
31. Basky G: All hands on deck as cases of COVID-19 surge. Canadian Medical Association Journal 2020, 192(15):E415-E416.

32. Harvey A: Covid-19: medical students should not work outside their competency, says BMA. BMJ 2020, 368:m1197.

33. David Gibbes Miller LP, Samuel Doernberg: The Role of Medical Students During the COVID-19 Pandemic. Annals of Internal Medicine 2020, 0(0):null.

34. Kalet AL, Jotterand F, Muntz M, Thapa B, Campbell B: Hearing the Call of Duty: What We Must Do to Allow Medical Students to Respond to the COVID-19 Pandemic. WMJ : official publication of the State Medical Society of Wisconsin 2020, 119(1):6-7.

35. Stetson GV, Kryzhanovskaya IV, Lomen-Hoerth C, Hauer KE: Professional identity formation in disorienting times. Medical education 2020, n/a(n/a).

36. Saibene AM, Allevi F, Biglioli F, Felisati G: Role and Management of a Head and Neck Department during the COVID-19 Outbreak in Lombardy. Otolaryngology-Head and Neck Surgery 2020, 0(0):0194599820917914.

37. Ross SW, Lauer CW, Miles WS, Green JM, Christmas AB, May AK, Matthews BD: Maximizing the Calm before the Storm: Tiered Surgical Response Plan for Novel Coronavirus (COVID-19). Journal of the American College of Surgeons 2020, 230(6):1080-1091.e1083.

38. Niska R.W. BCW: Bioterrorism and mass casualty preparedness in hospitals: United States, 2003; 2005.

39. Martin SD, Bush AC, Lynch JA: A national survey of terrorism preparedness training among pediatric, family practice, and emergency medicine programs. Pediatrics 2006, 118(3):e620-626.

40. Chong A, Kagetsu NJ, Yen A, Cooke EA: Radiology Residency Preparedness and Response to the COVID-19 Pandemic. Academic radiology 2020, 27(6):856-861.

41. Eva KW: Strange days. Medical education 2020, 54(6):492-493.

42. Cao W, Fang Z, Hou G, Han M, Xu X, Dong J, Zheng J: The psychological impact of the COVID-19 epidemic on college students in China. Psychiatry research 2020, 287:112934.

43. Ullah R, Amin S: The psychological impact of COVID-19 on medical students [Letter]. Psychiatry research 2020, 288:113020.

44. Solomon HV: COVID-19 checklist: Mask, gloves, and video chatting with grandpa. Psychiatry research 2020, 288:112986.

45. Rimmer A: Covid-19: what do trainees need to know? BMJ 2020, 368:m1276.

46. Warhadpande S, Khaja MS, Sabri SS: The Impact of COVID-19 on Interventional Radiology Training Programs: What You Need to Know. Academic radiology 2020, 27(6):868-871.

47. Clark VE: Editorial. Impact of COVID-19 on neurosurgery resident research training. J Neurosurg 2020:1-2.

48. Wong CS, Tay WC, Hap XF, Chia FL: Love in the time of coronavirus: training and service during COVID-19. Singapore medical journal 2020.

49. Tabari $P$, Amini M, Moosavi M: Lessons learned from COVID-19 epidemic in Iran: The role of medical education. Medical teacher 2020:1-1. 
50. He K, Stolarski A, Whang E, Kristo G: Addressing General Surgery Residents' Concerns in the Early Phase of the COVID-19 Pandemic. Journal of surgical education 2020.

51. Liang ZC, Ooi SBS: COVID-19: A Singapore Orthopedic Resident's Musings in the Emergency Department. Academic Emergency Medicine 2020, 27(4):349-350.

52. Ross JE: Resident Response During Pandemic: This Is Our Time. Annals of Internal Medicine 2020, 0(0):null.

53. Gallagher TH, Schleyer AM: "We Signed Up for This!" - Student and Trainee Responses to the Covid-19 Pandemic. New England Journal of Medicine 2020.

54. Gautam M, Kaur M, Mahr G: COVID-19-Associated Psychiatric Symptoms in Health Care Workers: Viewpoint From Internal Medicine and Psychiatry Residents. Psychosomatics 2020.

55. Grant-Kels JM: Invited response to the comment on "Dermatology residents and the care of COVID-19 patients". Journal of the American Academy of Dermatology 2020.

56. Patel B: Comment on "Dermatology residents and the care of COVID-19 patients". Journal of the American Academy of Dermatology 2020.

57. Culp BM, Frisch NB: COVID-19 Impact on Young Arthroplasty Surgeons. The Journal of arthroplasty 2020:S0883-5403(0820)30446-30440.

58. Menon A, Klein EJ, Kollars K, Kleinhenz ALW: Medical Students Are Not Essential Workers: Examining Institutional Responsibility During the COVID-19 Pandemic. Academic Medicine 2020, Publish Ahead of Print.

59. Agarwal V, Gupta L, Davalbhakta S, Misra D, Agarwal V, Goel A: Undergraduate medical students in India are underprepared to be the young-taskforce against Covid-19 amid prevalent fears. medRxiv

2020:2020.2004.2011.20061333.

60. Khan S, Khan M, Maqsood K, Hussain T, Noor-ul-Huda, Zeeshan M: Is Pakistan prepared for the COVID-19 epidemic? A questionnaire-based survey. Journal of Medical Virology 2020, $\mathbf{n} / \mathbf{a}(\mathrm{n} / \mathrm{a})$.

61. Bhagavathula AS, Aldhaleei WA, Rahmani J, Mahabadi MA, Bandari DK: Knowledge and Perceptions of COVID-19 Among Health Care Workers: Cross-Sectional Study. JMIR Public Health Surveill 2020, 6(2):e19160.

62. Burhan Dost EK, Özlem Terzi, Sezgin Bilgin, Yasemin Burcu Ustun, Hatice Nilden Arslan: Attitudes of Anesthesiology Specialists and Residents toward Patients Infected with the Novel Coronavirus (COVID-19): A National Survey Study. Surgical Infections 2020, 21(4):350-356.

63. Taghrir MH, Borazjani R, Shiraly R: COVID-19 and Iranian Medical Students; A Survey on Their Related-Knowledge, Preventive Behaviors and Risk Perception. Arch Iran Med March 2020, 23(4):249-254.

64. Alzoubi H, Alnawaiseh N, Al-Mnayyis A, Lubad M, Aqel A, Al-Shagahin H: COVID-19-knowledge, attitude and practice among medical and nonmedical University Students in Jordan. J Pure Appl Microbiol 2020, 14:17-24.

65. DeFilippis EM, Ranard LS, Berg DD: Cardiopulmonary Resuscitation During the COVID-19 Pandemic: A View from Trainees on the Frontline. Circulation 2020, 0(0). 
66. Gilbert A: Trainees and COVID-19: A Call to Arms. The American Journal of Forensic Medicine and Pathology 2020, Publish Ahead of Print.

67. Poonia SK, Rajasekaran K: Information Overload: A Method to Share Updates among Frontline Staff during the COVID-19 Pandemic. Otolaryngology--head and neck surgery : official journal of American Academy of Otolaryngology-Head and Neck Surgery 2020:194599820922988.

68. Kim H: Outbreak of novel coronavirus (COVID-19): What is the role of radiologists? European Radiology 2020, 30(6):3266-3267.

69. Wujtewicz M, Dylczyk-Sommer A, Aszkiełowicz A, Zdanowski S, Piwowarczyk S, Owczuk R: COVID-19 - what should anaethesiologists and intensivists know about it? Anaesthesiology intensive therapy 2020, 52(1):34-41.

70. Rimmer A: Trainees and covid-19: your questions answered. BMJ 2020, 368:m1059.

71. Rimmer A: Covid-19: trainees will not move jobs in April. BMJ 2020, 368:m1088.

72. Guidance on medical students' clinical participation: Effective immediately. [https://lcme.org/wp-content/uploads/filebase/March-17-2020-Guidance-onMediical-Students-Clinical-Participation.pdf]

73. Abdessater M, Rouprêt M, Misrai V, Matillon X, Gondran-Tellier B, Freton L, Vallée M, Dominique I, Felber M, Khene ZE et al: COVID19 pandemic impacts on anxiety of French urologist in training: Outcomes from a national survey. Progrès en Urologie 2020.

74. Soled D, Goel S, Barry D, Erfani P, Joseph N, Kochis M, Uppal N, Velasquez D, Vora K, Scott KW: Medical Student Mobilization During A Crisis: Lessons From A COVID-19 Medical Student Response Team. Academic Medicine 2020, Publish Ahead of Print.

75. Rimmer A: Covid-19: junior doctor calls on colleagues to gather supplies for staff working long hours. BMJ 2020, 368:m1072.

76. Rakowsky S, Flashner BM, Doolin J, Reese Z, Shpilsky J, Yang S, Smith CC, Graham K: Five Questions for Residency Leadership in the Time of COVID19: Reflections of Chief Medical Residents From an Internal Medicine Program. Academic Medicine 2020, Publish Ahead of Print.

77. Harrington RA, Elkind MSV, Benjamin IJ: Protecting Medical Trainees on the COVID-19 Frontlines Saves Us All. Circulation 2020, 141(18):e775-e777.

78. Information for medical students [https://www.gmc-uk.org/news/newsarchive/coronavirus-information-and-advice/information-for-medical-students]

79. Dieckmann P, Torgeirsen K, Qvindesland SA, Thomas L, Bushell V, Langli Ersdal $\mathrm{H}$ : The use of simulation to prepare and improve responses to infectious disease outbreaks like COVID-19: practical tips and resources from Norway, Denmark, and the UK. Advances in Simulation 2020, 5(1):3.

80. Villa A, Sankar V, Shiboski C: Tele(oral)medicine: A new approach during the COVID-19 crisis. Oral Diseases 2020, n/a(n/a).

81. Dinh TT, Halasz LM, Ford E, Rengan R: Radiation Therapy in King County, Washington During the COVID-19 Pandemic: Balancing Patient Care, Transmission Mitigation, and Resident Training. Advances in radiation oncology 2020. 
82. Park J, Rhim HC: Consequences of coronavirus disease 2019 on international medical graduates and students applying to residencies in the United States. Korean J Med Educ 2020, 32(2):91-95.

83. Dyer GSM, Lipa SA: What's Important: COVID-19-Helpers, Not Heroes. JBJS 2020, Latest Articles.

84. Rimmer A: How can I cope with redeployment? BMJ 2020, 368:m1228.

85. Escalera-Antezana JP, Cerruto-Zelaya PE, Apaza-Huasco M, Miranda-Rojas SH, Flores-Cárdenas CA, Rivera-Zabala L, Olmos-Machicado JR, Alvarez-Amaya V, Acevedo-López D, Valencia-Gallego V et al: Healthcare workers' and students' knowledge regarding the transmission, epidemiology and symptoms of COVID-19 in 41 cities of Bolivia and Colombia. Travel medicine and infectious disease 2020:101702.

86. Christensen L, Rasmussen CS, Benfield T, Franc JM: A Randomized Trial of Instructor-Led Training Versus Video Lesson in Training Health Care Providers in Proper Donning and Doffing of Personal Protective Equipment. Disaster medicine and public health preparedness 2020:1-15.

87. Rimmer A: Covid-19: Health Education England shares advice for trainees. BMJ 2020, 369:m1635.

88. Covid-19: medical students requested to work in the NHS. [https://beta.bma.org.uk/advice-and-support/covid-19/your-contract/covid-19medical-students-requested-to-work-in-the-nhs]

89. DeWitt DE: Fighting COVID-19: Enabling Graduating Students to Start Internship Early at Their Own Medical School. Annals of Internal Medicine 2020, 0(0):null.

90. Stokes DC: Senior Medical Students in the COVID-19 Response: An Opportunity to Be Proactive. Academic Emergency Medicine 2020, 27(4):343345.

91. Representatives of the STARSurg Collaborative EC, and TASMAN Collaborative: Medical student involvement in the COVID-19 response. Lancet (London, England) 2020, 395(10232):1254.

92. Stoj VJ, Grant-Kels JM: Dermatology residents and the care of patients with coronavirus disease 2019 (COVID-19). Journal of the American Academy of Dermatology 2020, 82(6):1572-1573.

93. Cantave M, Perlson J, Lewis C, Byers B: COVID-19 Reveals Why We Need Physician-Advocates Now. Academic Medicine 2020, Publish Ahead of Print. 


\section{Declarations}

Ethics approval and consent to participate

- Not applicable

Consent for publication

- Not applicable

Competing interests

- None

Funding

- None

Authors' contributions

- BW concept, literature search and analyzation, main writer of the review

- BG concept, proofreading

- WH concept, proofreading

All authors read and approved the final manuscript.

Acknowledgements

- None 
Figures

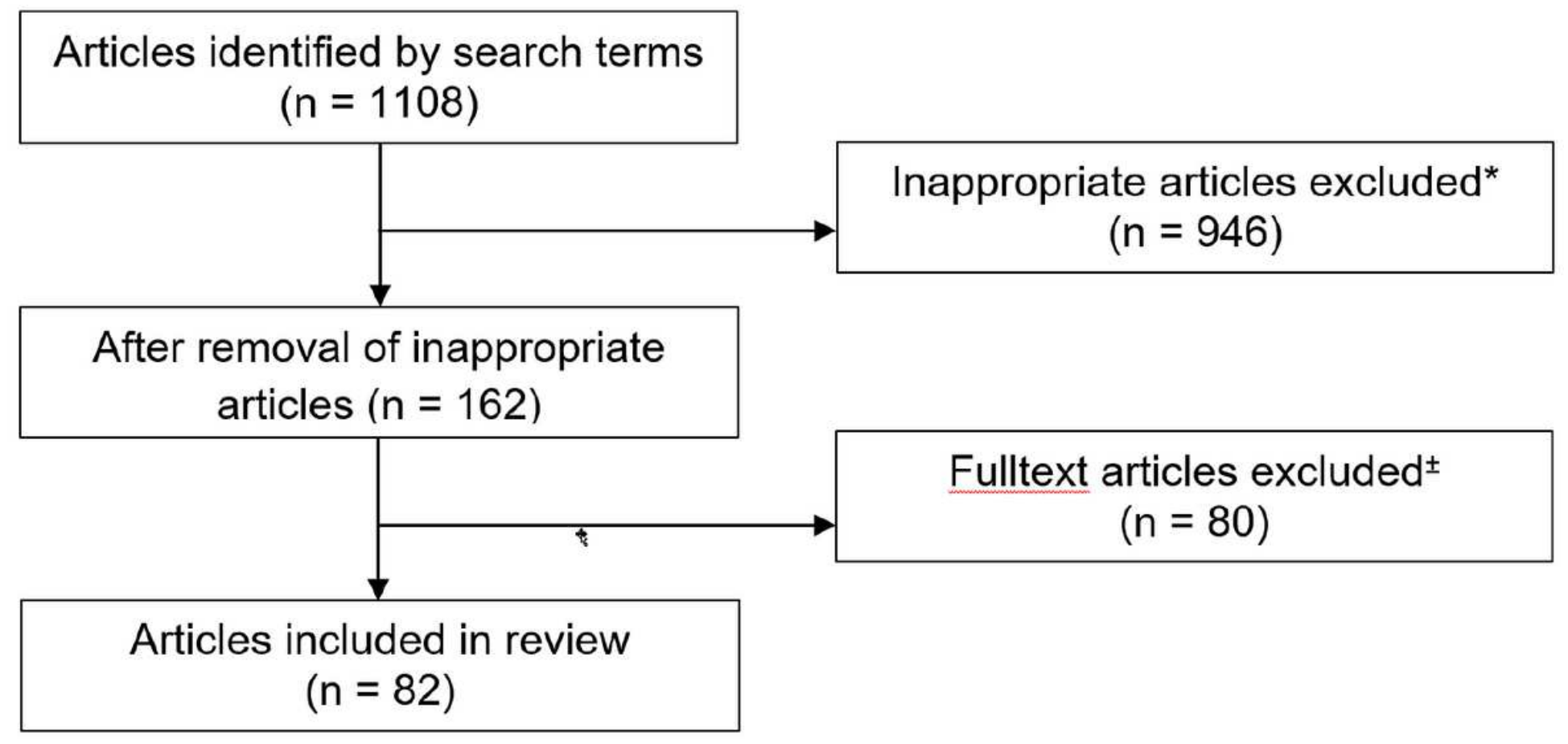

Figure 1

Process flowchart of article selection. *inappropriate articles primarily resulted from articles in the pandemic that refer to 1 . Residents and residency in terms of inhabitants or 2. Students, not in the sense of medical students or 3 . Education, not in the sense of medical education. \pm exclusion of articles solely dealing with adaptation of curricula. 


\section{Number of identified articles over time}

90

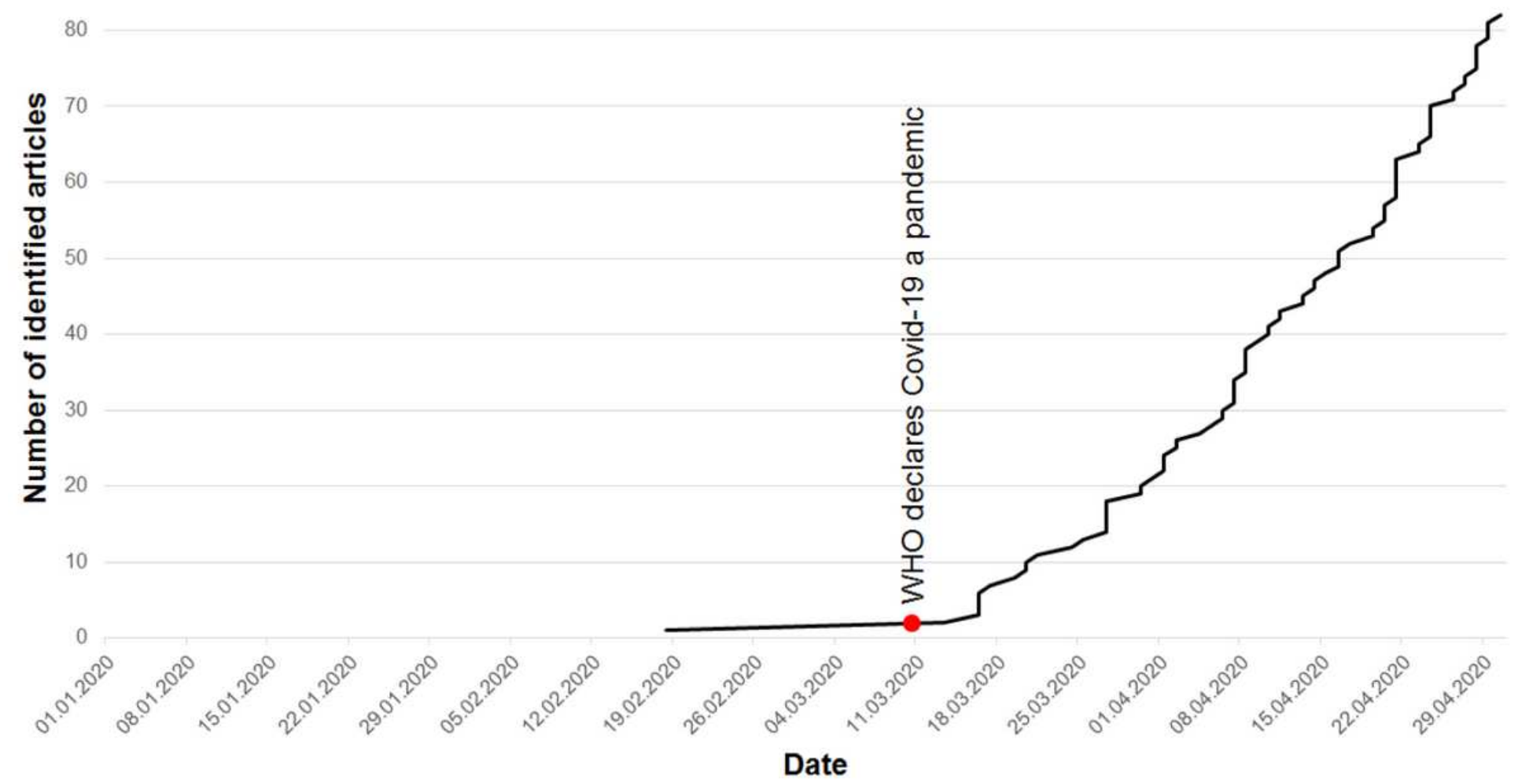

Figure 2

Number of identified articles over time 